\title{
The experience of women with genital prolapse
}

\author{
L Roets, Ph.D \\ School of Nursing, Faculty of Health Sciences, University of the Free State.
}

\section{Correspondence address:}

Dr L Roets

School of Nursing

Faculty of Health Sciences

University of the Free State

Bloemfontein

Tel : (051) 401-3536

Fax : (051)401-9140

E-mail:gnvklr.md@mail.uovs.ac.za

\section{Abstract: Curationis $30(3): x-y$}

The concept genital prolapse indicates the transposition of the pelvic organs. These include the bladder, uterus, vaginal dome and the rectum. Regardless of the stage of genital prolapse, it can have a drastic influence on the quality of a woman's life. It may lead to incontinence of urine and faeces, sexual problems as well as pelvic discomfort. The way in which a patient experiences these symptoms is of value to the nurse for whom holistic care is important. The aim of this study was, therefore, to describe the experiences of women with a diagnosis of genital prolapse.

A qualitative study was carried out from a phenomenological viewpoint. Individual in-depth interviews were used as the method of data collection. The interviews took place in a relaxed, familiar environment. One open-ended question was asked, namely: "Please describe to me how you experience the symptoms of your condition."

A total of 19 interviews were conducted of which eight respondents had a Stage 1 genital prolapse, eight a Stage 2 and only three respondents had a Stage 3 genital prolapse.

The data collection and analysis processes were integrated as each interview was transcribed directly afterwards, after which the process of analysis was commenced. The following categories regarding the experience of genital prolapse were identified from the data: emotional experiences, self-esteem, social interaction, physical discomfort and teaching and learning.

The findings were that quality of life and social behaviour may be negatively influenced. The self-image of a woman with genital prolapse is affected and emotions that include anxiety, aggression, frustration and despondency may be experienced. Urinary incontinence compelled some of the respondents to wear sanitary pads, and often restricted their social lives.

It may be possible to teach women about their condition, symptoms and treatment options by means of information leaflets. Health care workers must be made aware of the uniqueness of each patient and that not everyone experiences symptoms in the same way.

\section{Introduction and problem statement}

Genital prolapse refers to the downward or forward transposition of the pelvic organs. These include the bladder, uterus, vaginal dome and the rectum (Scott, Di Saia, Hammond \& Spellacy, 1999:713). Genital prolapse can be divided into three stages and the specific stage is determined by means of a vaginal examination as described by Scott, et al. (1999:723):

- $\quad$ Stage 1 - The most distal part of the prolapse is $>1 \mathrm{~cm}$ above the hymenal ring

- $\quad$ Stage 2 - The most distal part of the prolapse is between $1 \mathrm{~cm}$ above and $1 \mathrm{~cm}$ below the hymenal ring

- $\quad$ Stage 3 - The most distal part of the prolapse is $>1 \mathrm{~cm}$ below the hymenal ring and not more than $2 \mathrm{~cm}$ outside the vagina (Scott, et al., 1999:723)

It can have a drastic influence on the quality of a woman's life, regardless of 
the stage of genital prolapse (Bonetti, Erpelding \& Pathak, 2004:167). It may lead to urinary and faecal incontinence, sexual problems as well as local pelvic discomfort (Thaker \& Stanton, 2002:1258). Symptoms such as urinary incontinence may be such a bad experience that patients do not wish to discuss it even with their doctor. They often feel ashamed or think that such symptoms may be normal (Dugan, Roberts, Cohen, Presser, Davis, Bland \& Albertson, 2002:4; Kumari, Walia \& Sing, 2000:348).

The experience of these symptoms by patients with genital prolapse is of value to the nurse for whom holistic nursing is important. Nurses must understand how patients experience their symptoms if they wish to deliver optimum care.

The aim of this study was, therefore, to describe how women with a diagnosis of genital prolapse experience their symptoms.

\section{Research design and technique}

A qualitative study was undertaken from a phenomenological viewpoint. According to Burns \& Grove (2005:31) phenomenological research is ideal for researching and giving meaning to a person's experience in his/her environment, in this case women's experience of genital prolapse (Bassett, 2004:166)

Individual in-depth interviews were used as the method of data collection. The aim of an in-depth interview is to obtain access to another person's life in an empathetic manner (Silverman, 2005:116) and not to identify the objective truth or to test preconceived hypotheses. They are conducted purely to determine the experience of a condition or event as described by the person involved (Doyle, 2001:4).

The in-depth interviews took place in a relaxed, familiar environment, namely the respondents' homes. Verbal as well as written consent to the interview were obtained from the participants. All interviews were taped and transcribed immediately after the interview. A cocoder was involved to ensure accurate transcription and coding (Brink, 2006:185). Only one open-ended question was asked, namely: "Please describe to me how you experience the symptoms of your condition". All communication skills were used to ensure an open discussion in order to make it possible to describe the experiences.

\section{Unit of analysis}

The unit of analysis consisted of white women between the ages of 40 and 80 years who lived in Bloemfontein and who had been diagnosed with genital prolapse.

Possible participants were excluded if they:

- Were pregnant;

- Had previously been treated for cancer in the abdomen or pelvis;

- Were bedridden, immobile or in a wheelchair or

- $\quad$ Had been diagnosed with senility or Alzheimer's disease.

Staff members of the Department of Obstetrics and Gynaecology of the University of the Free State identified the women with genital prolapse as well as the stage of the condition.

A convenience sample was selected after the diagnoses were confirmed. Each selected participant was personally approached to participate in the study. After they had agreed to take part an appointment was made for the in depth interview at a time and place convenient to the participant. All the interviews were conducted in the comfort of the respondents' own homes as this was what they preferred and their privacy could be assured in this way (Brink, 2006:153).

Interviews were conducted with participants in all stages of genital prolapse until saturation of data was achieved. Saturation was achieved when no new themes or descriptions could be identified and no new data were gathered (Polit \& Beck, 2004:57).

\section{Data analysis}

The data analysis process as described by Colaizzi (in Bassit, 2004:166), was used. Transcriptions were read, re-read and read again in order to identify and group together concepts and experiences. Eventually the following categories regarding experiences of genital prolapse were identified: emotional experiences, self-esteem, social interaction, physical discomfort and teaching and learning.

\section{Trustworthiness}

The most important principle regarding the trustworthiness of qualitative research is the ability of the research to interpret the experiences of the participants very accurately (Speziale $\&$ Carpenter, 2003:38; Brink, 2006:118). The following important principles and terms must be taken into account according to de Vos, Strydom, Fouché and Delport (2004:351): credibility, transferability, reliability and conformability.

\section{Credibility}

One of the best ways of ensuring credibility is to have been in the field of research for a considerable time (Speziale \& Carpenter, 2003:380). The researcher had been involved with the participants during a genital prolapse prevalence study and could therefore follow them up and support them directly after their diagnosis as she had already built a relationship of trust with them.

Another prerequisite is to ensure that the data given by a participant is regarded as an accurate description of their experiences (Brink, 2006:118). The researcher showed the data to the participants in order to ensure that it was a correct reflection of their feelings.

\section{Transferability}

Transferability refers to the possibility that others in similar circumstances can identify with the data. Unfortunately this aspect does not lie with the researcher, but with future users of the data (Speziale \& Carpenter, 2003:39).

\section{Dependability}

The dependability of a study means that the data is to be trusted, therefore an audit needs to be done on the gathered data (Brink, 2006:119; Polit \& Beck, 2004:435). All the interviews were conducted by the researcher herself after she had successfully completed the necessary training in interviewing. The interviews were transcribed directly after they had taken place and a co-coder evaluated the transcriptions for a correct version. The process of analysis was also carried out with the co-coder. After this all data was returned to the participants to ensure that it was a correct version of their experiences. 


\section{Confirmability}

Confirmability means the assurance that the recommendations and conclusions are supported by the study data and that the interpretation of the researcher and the actual data correspond (Brink, 2006:119).

All interviews were taped, transcribed, coded and analyzed by the researcher herself after which they were presented to the co-coder for verification and to the participants to ensure that the data could be confirmed.

\section{Ethical aspects}

The collection, processing and making known of the data all took place in terms of ethical principles. Ethical principles comprise, among others, respect for, fairness to, and the safety of people so that they are never harmed (Burns \& Grove, 2005:735; Polit \& Beck, 2004:134154; Babbie, 2004:63).

Written consent was obtained before commencement of the study from the Ethical Committee of the Faculty of Health Sciences of the University of the Free State, as well as from every participant.

Participants were aware of the fact that they could withdraw at any time should they so wish. They were aware that the interview would be taped and transcribed, but that the data would be known only to the researcher and that no identifiable data would be made known in the research report.

The privacy of participants and the confidentiality of the collected data were therefore assured at all times.

\section{Data interpretation and checking of the literature}

In view of the fact that the experiences of the participants in all three stages of genital prolapse were predominantly similar, only those aspects that showed substantial differences in the three stages, will be discussed. Substantial differences referred to different experiences that were expressed by more than one participant.

The experience of women with genital prolapse will be discussed in terms of the main categories, as identified, after a brief overview of the unit of analysis has been given.

\section{Description of the unit of analysis}

The ages of the participants varied from 48 to 77 years, with an average of 67 years. Only one woman was a nullipara, six had a parity of two, six a parity of three and five a parity of four, while only one respondent had a parity of five. Most participants (16), had had vaginal deliveries, followed by two caesarean sections and one assisted delivery.

\section{Emotional experiences}

Women with genital prolapse sometimes experience the symptoms very intensely and feel that they do not even want to discuss them with their doctor. They often feel ashamed of the urinary incontinence or they believe that it is probably normal to be incontinent (Dugan et al., 2002:4; and Kumari et al., 2000:348).

The emotional experiences of the participants are set out in Figure 1.

\section{Shame}

According to Hampel et al., (2004:25) and Dugan et al., (2002:5) women with urinary incontinence experience a feeling of shame which concurs with the research findings of this study in which six of the participants stated that they were just too ashamed to speak to anyone about their condition.

\section{“... I have never spoken to anvone about it ..." \\ "... it is a worse embarrassment to go to the doctor and with the examinations. I find it bad ... very, very bad. That is why I will not easily go again ..."}

Bonetti et al., (2004:172) also found that
Theme

Shame

Anxiety

Aggression and frustration

Despondency

Unpleasant

Acceptance women with genital prolapse withdrew from social situations precisely due to shame about their condition.

\section{Anxiety}

Anxicty is often caused by a feeling of uncertainty or fear (Morris \& Maist, 2002:452). The fact that the 19 participants expressed their feeling of anxiety 48 times indicates that these participants were anxious. Anxiety was due to urinary incontinence, among others.

“... I am afraid if there are people ... it will leak, you know ..."

"... you are always afraid you won't reach the toilet in time..."

Fourteen participants mentioned that urinary incontinence made then anxious, which compares with Hampel et al. $(2004: 25)$ who found that $62 \%$ of women with urinary incontinence felt anxious about their condition.

\section{Aggression and frustration}

Three participants experienced a feeling of aggression about their genital prolapse.

“... it just makes me angry, because it's a nuisance... I don't feel sorry that I have the problem, hm, I feel disgusted that I have the problem ..."

Pain or frustration often leads to aggression although frustration does not always do so (Morris \& Maisto, 2002:366). In accordance with the results of a study by Hampel, Artibani, Pons, Haab, Jackson, Romero, Gavart and Papanicaou (2004:25) in which women with urinary incontinence sometimes experienced frustration as a result of their condition, participants in this study described their feeling of frustration and aggressions as follows: 


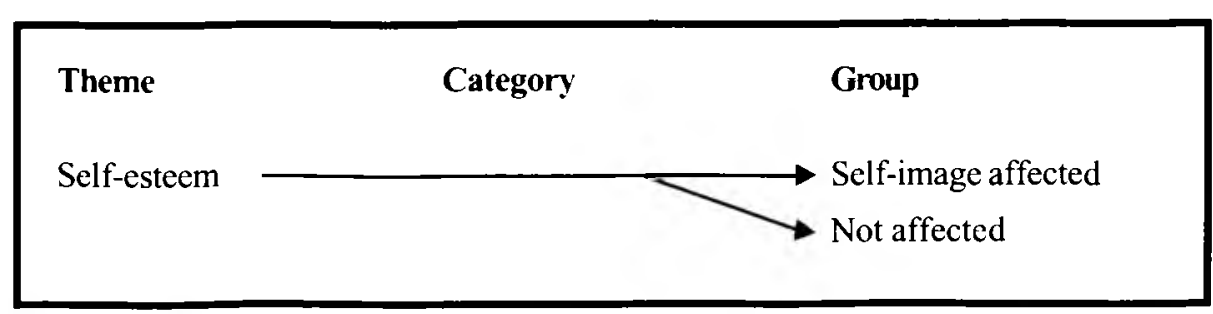

“... then it's wet somewhere, a leak that frustrates me terribly..."

\section{Despondency}

Sixteen participants described their feeling of despondency 32 times and said that prolapse made them really despondent.

“... Oh well, so I carry on like this ..."

Most responses (22) were obtained from participants with stage l prolapse. It may be that these participants were still in the early stage of their illness while the others had been living with the symptoms for a long time, as many of them described it:

“... I'm so used to this, I suppose it's normal to be like this ..."

\section{Unpleasant}

The experience described as unpleasant was the response most stated and described by all the participants about their illness.

\section{“... it's very bad, you know: Oh! Ifind it} very bad..."

Altogether 74 responses about this unpleasantness were given by the 19 respondents. Aspects described as unpleasant were urinary incontinence, anal incontinence, constipation, visits to the doctor and urinary retention.

The participants experienced urinary incontinence as the most unpleasant with a total of 51 responses to this aspect.

“... what I find very bad is when you're wearing underwear and you sneeze or something, then your underwear is always wet. I find that very bad..."

\section{Acceptance}

An interesting finding was that all three the participants with Stage 3 genital prolapse stated that they had accepted their condition. Six of the eight participants with Stage 2 genital prolapse indicated that they had made peace with their condition.

"... you know, I always think there are worse things that can happen to you ... I am so used to it now ..." 1 prolapse had not accepted their condition so readily and only two of the eight indicated that they had done so. It may be that, as is the case with so many other diseases, acceptance comes eventually and that these participants had not yet had enough time to accept their condition.

The next category identified from the interviews was that of self-esteem.

\section{Self-esteem}

Any deviation from the normally acceptable appearance or functioning of body parts may result in a low self-image or self-esteem. A negative self-image often relates to the fact that people focus to determine their self-image. They require constant external stimuli to improve it (Tyrrell, 2006:online; Ruy, 2006:online). People who experience symptoms such as urinary incontinence due to genital prolapse may therefore no longer have a good self-image. This category of responses as identified in the research is reflected in Figure 2.

\section{Self-image}

Dugan et al. (2002:5) is of the opinion that $73 \%$ of women with urinary incontinence feel that their self-image has been affected by the condition. In this research six of the 19 participants mentioned that genital prolapse had affected their self-image, that is, $32 \%$ of the participants.

“... you know, one always feels sort of self-conscious ..."

With a total of 12 responses, seven of which came from the Stage 1 prolapse group, it would appear that women with Stage 1 genital prolapse more often feel
In contrast, the participants with a Stage only on what they can do and accomplish
A single participant with Stage 2 genital prolapse mentioned pertinently that genital prolapse had not affected her selfimage.

\section{“... it does not affect my humanity or my} femininity ..."

Possibly this participant had a particularly good self-image or had accepted her illness to such an extent that it had in no way affected her view of herself.

\section{Social interaction}

\section{Activities}

A number of studies about the experiences of genital prolapse have shown that this condition has a definite influence on the quality of life of women (Bonetti et al., 2004:167; Dugan, Roberts, Cohen, Presser, Davis, Bland \& Albertson, 2002:5). The participants confirmed this by describing how they adapted their daily activities around social activities by, for instance, more regular visits to the toilet, the use of sanitary pads, pelvic muscle exercised as well as physical toilet habits. Compare Figure 3 for a schematic representation of the groups and themes regarding social intercourse.

\section{Social activities}

It is well-known that a good self-image leads to social interaction and intercourse (Cash \& Puzinski, 2002:281). It is therefore not surprising that women with urinary incontinence often restrict themselves socially to try and keep their condition secret (Doughty, 2000:36).

\section{“... I am far more housebound, as I don't like to go to places with people any more ..."}

According to Doughty (2000:39) it depends on the type of incontinence whether women restrict themselves socially. Anal incontinence has a greater effect than urinary incontinence, but in the case of urinary incontinence urgency places greater limitations on women than stress incontinence.

Finding available toilet facilities can therefore be a great source of tension to women with incontinence (Newman \& Giovannini, 2002:39) as they cannot go out and socialize easily due to the limitation caused by their incontinence. 
Category

Social interaction

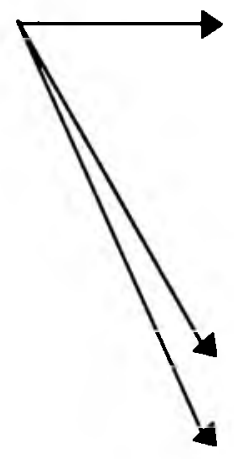

Group

Theme

Activities and rest

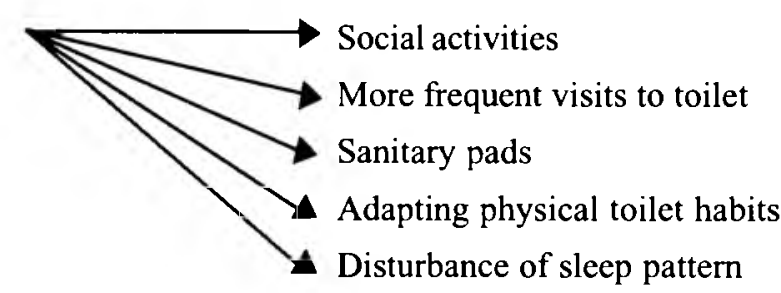

Hygiene

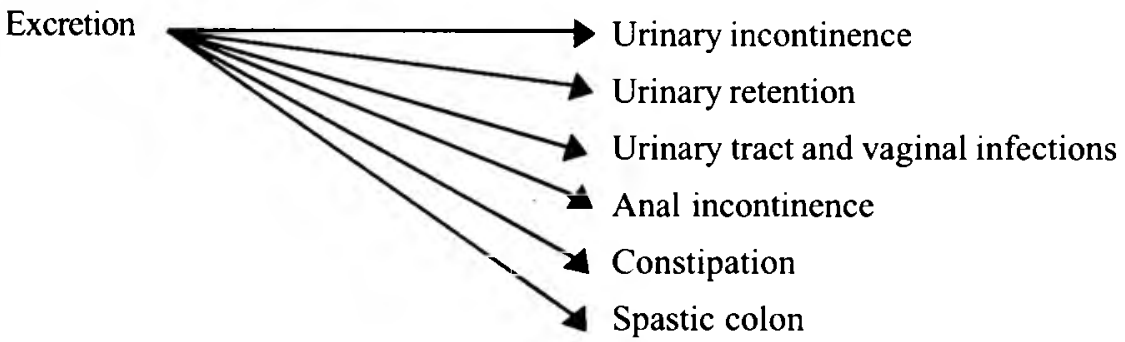

“... I become tense if I have to go anywhere as the first thing I think of is 'are there toilet facilities '..."

"... you must always plan things so that you will always be near a facility ..."

It was interesting to note that not one respondent with Stage 3 genital prolapse mentioned that their social activities were limited. On the contrary, two responses of the participants with Stage 3 prolapse clearly indicated that they did not limit their social activities.

“... it has not influenced my activities, that I go out less frequently. Ifeel that it does not bother others, they are not aware of it ..."

\section{More frequent visits to the toilet}

The specific most frequent response of participants in all stages, about frequency ( 32 responses) was the fact that they needed to visit the toilet so often. More visits to the toilet indicates urinary frequency and urgency and can be due to a cystocele and/or urethrocele (Drife \& Magowan, 2004:241) from which these participants suffered.

“... I go to the toilet more regularly. If you feel you must go, you must go immediately, not a little later as you would under normal circumstances. You must go immediately ..."

“... I must go to the toilet often ..."
The responses of the participants show clearly that social interaction is negatively influenced.

\section{Sanitary pads}

Seventy-three per cent of women with genital prolapse are often obliged to wear sanitary pads because of their urinary incontinence (Ellerkman, Cundiff, Melick, Nihira, Leffler \& Bent, 2001:1334) to ensure dry underwear.

Eight participants in this study stated that they needed to wear sanitary pads and confirmed that this was due to their urinary incontinence.

“... so u use pads day and night. They just make me feel more comfortable. As I say, I don't have to worry that I may wet myself..."

“... You know, it's terribly uncomfortable, as I now wear pantyliners ..."

\section{Adapting physical toilet habits}

There are conflicting reports in the literature about the incidence of cases where women need to adapt their physical toilet habits in order to pass urine or stools. According to Kumari, Walia \& Singh (2000:344) it occurs in extreme cases that women need to support themselves in some way or other in order to be able to urinate or pass a stool. Ellerkman et al. (2001:1335) found that $40 \%$ of the women with genital prolapse had to change their position to make excretion possible.

The need to change position during urination or passing a stool is associated with an increase in the prolapse of the anterior dome or uterus prolapse (Donohue, 2001:11). In this study three of the 19 participants stated that their physical toilet habits had to be adapted.

“...then it works like a kettle, empties, I stand up for a few seconds, and bend forward again. I empty two or three times at a time ..."

\section{Experience no activity adaptations}

An interesting fact was that 18 of the participants verbalized the above adaptations during the interview, but that they did not experience them as true adaptations. Seventeen participants stated 40 times that they did not really feel that they had adapted their activities.

“... it does not affect my daily activity at all ... I carry on with my activities ..."

Yet, as previously mentioned, they wear sanitary pads, visit the toilet more often, need to adapt their position on the toilet, and so forth. It may be that women view genital prolapse as a normal part of ageing and therefore regard it as "normal" (Dugan, etal., 2002:5). 
Eleven participants stated that their sleep pattern was disturbed due to nocturia. Nocturia may be associated with genital prolapse, especially where urgency is associated with incontinence (McCarthy \& Hunter, 2003:255).

“... all I can say to you is that it is a bother at night, because I have to get up sometimes. I get up twice in the night, sometimes up to three times a night ..."

One respondent in each group stated that they found the disturbance of their sleep pattern irksome.

“... I am a poor sleeper, so it's bad when my bladder also troubles me ..."

It would appear that all participants did not experience the disturbance of their sleep pattern negatively.

“... I suppose if I was not such a good sleeper it would probably worry me, but you know, I wake up and get up half asleep, go to the toilet, get into bed and sleep ... No it does not worry me ..."

\section{Hygiene}

According to Newman and Giovannini (2002:39) patients with urinary incontinence are inclined to concentrate more on their personal hygiene in an attempt to keep their condition a secret. The responses of the participants in this study were in accordance with those findings as reflected in their responses:

“... I can't handle the smell at all. I wash three times a day, or more, it depends how bad it is ..."

"... it definitely affects one ... I don't feel ... so clean any more ..."

\section{Excretion \\ Urinary incontinence}

Urinary incontinence is one of the commonest symptoms of genital prolapse and $73 \%$ of women with this condition suffer from it (Ellerkman et al., 2001:1332). Loss of support of the urethra and lower vaginal wall can be associated with urinary incontinence (Scott et al., 1999:724).

In this study 18 of the respondents experienced a degree of urinary incontinence - they spoke about the problem 81 times.

“... when it's just a little full and you can't go to the bathroom immediately it leaks, not much, but it leaks ..."

“... when my bladder is full it simply overflows ... when it overflows, it overflows, it doesn 't just drip, it overflows ..."

It is clear from the above that the participants experienced urinary incontinence very negatively.

\section{Urinary retention}

Loss of support of the higher vaginal wall and the base of the bladder as associated with problems related to emptying the bladder (Scott et al., 1999:724). Problems in this regard were also mooted by participants in this study.

“... I have a need, I must go, but it is so painful, it goes into a spasm and I can't ..."

The response regarding urinary retention increased as the stage of genital prolapse worsened. Only one response of a participant with Stage 1 genital prolapse to as many as five responses of respondents with Stage 3 prolapse described problems with urinary retention.

\section{Urinary tract and vaginal infection}

Genital prolapse can cause vaginal or urinary tract infections (Bonetti et al. 2004:171). A large cystocele can cause the bladder not to empty completely with the result that recurrent urinary tract infections are common among women with genital prolapse (Drife \& Magowan, 2004:241). Participants in this study also complained of urinary tract and vaginal infections.

\section{“... I often get bladder infections ..." \\ "... the constant vaginal infections are bad ..."}

\section{Anal incontinence}

Anal incontinence is defined as the involuntary passing of flatus, fluid or solid stools (Meschia, Buonaguidi, Pifarotti, Somigliana, Spennacchio \& Amicarelli, 2002:719). According to Ellerkman et al (2001:1334) 31\% of women with genital prolapse experience anal incontinence.

\section{"... because if my bowels don't act, then after a while it just comes out ..."}

In the research study five of the 19 participants stated that they experienced anal incontinence. These respondents all suffered from Stage 2 and 3 prolapses which supports the findings of Meschia et al (2002:720) that the prevalence of anal incontinence increases as genital prolapse becomes worse.

\section{Constipation}

Ellerkman et al (2001:1334) found that $66 \%$ of women with genital prolapse experienced constipation, while $43 \% * 8$ ) of the participants in this study mentioned their constipation. The respondents in this study stated that they used coping mechanisms such as adapting their diet or taking laxatives to overcome the problem.

“... I do have a problem with constipation, but eating sensibly, for instance dried peaches, does help a lot ..."

“... sometimes I went for up to a week without a bowel movement, it was bad, it was very, very bad. I tried almost everything under the sun. I now take $X X X$ - I take about two mouthfuls every other day and I have bowel movements and otherwise I have a normal life."

\section{Spastic colon}

Genital prolapse may lead to symptoms of spastic colon (Barber, Kuchibhatla, Pieper \& Bump, 2001:1389; Meschia et al., 2002:721). In this study eight of the participants stated that they suffered from a spastic colon.

“... I have a thing here that is terribly painful, the doctor days she thinks it is spasm, colon spasm ..."

"...I always have stomach-ache. The doctor says it is a spastic colon ..."

All the respondents mentioned this spasm twice in their interviews therefore it may be accepted that they found it a very negative experience.

\section{Physical discomfort}

The experiences of respondents regarding physical discomfort are illustrated in Figure 4.

\section{Pain}

Genital prolapse may cause lower back pain as well as abdominal pain (Bonnetti et al., 2004:167). Participants in the study also experienced pain and verbalized it as follows:

“... my back gets very sore if I work in 


\section{Category \\ Group Theme \\ Physical discomfort

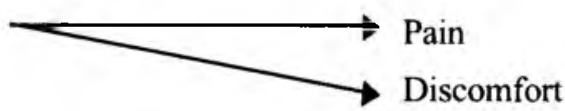

the garden too long, even now, if I work bending over for too long it hurts very, very much..."

This pain can be caused by extension of the utero-sacral ligaments that support the vagina and uterus (Scott et al., 1999:724) and is commonly experienced by patients with genital prolapse.

\section{Discomfort}

Women with genital prolapse may experience symptoms of discomfort due to prolapse of the uterus or dome. These symptoms include a heavy feeling in the pelvis, discomfort when standing or performing other physical activities, a sensation of low abdominal pressure or the prolapse in the vagina can be felt (Ellerkman et al., 2001:1334; Monahan, Sands, Neighbors, Mark \& Green, 2007:1694).

“... Yes, I feel it. That's what worried me in the first place. I asked what it was. Then the doctor told me it was my large bowel that came down when I strained ..." "... it's very uncomfortable, you know, because I now wear pantyliners ..."

\section{Teaching and learning}

It was clear from the responses of the participants that they had insufficient knowledge of their condition and that they would have liked to know more.

“... doctor says it presses on my bladder and it's true, because I can see after I've had a bowel movement more urine comes out. In other words it stops it from coming ..."

"... if you don't do that operation to lift the colon a little, the colon sometimes breaks, I don't know how or where, then everything is into you, into your intestines, if you don't have it operated on ..."

"... maybe you can tell me, but I don't know if it's supposed to be so sore ..." In view of the fact that women are often shy to discuss genital prolapse with others, even with their doctor (Dugan $e t$ al., 2002:4), it may be that these women are not informed and taught about the symptoms and treatment of genital prolapse. Health care workers must therefore be encouraged to broach the subject first and to provide thorough education and information to patients with genital prolapse.

\section{Conclusions and}

\section{recommendations}

A number of aspects of a woman's life are influenced by genital prolapse. The quality of her life may be negatively influenced or her daily activities may be influenced in a manner that many do not even notice.

This research study clearly shows that the self-image of women with genital prolapse is affected. They experience emotions regarding their condition that include shame, anxiety, aggression, frustration and despondency. Yet they really accept their condition.

Urinary incontinence is one of the most common symptoms of genital prolapse, but urinary retention, urinary tract and vaginal infections, anal incontinence, constipation and a spastic colon were also experienced by participants in this study. The respondents had individual experiences that often differed completely from those of others regarding some of the symptoms. However, negative feelings about every one of these symptoms were clearly expressed by the participants. As an example, personal hygiene was of the utmost importance as urinary and anal incontinence led to unpleasant odours, about which these participants were very sensitive.

The social behaviour and experiences of all the women with regard to their condition were not influenced to the same degree. Those with urinary incontinence restricted themselves socially to a greater extent than women who did not have this problem.

Some of the participants experienced a great deal of tension when toilet facilities were not available. Although $95 \%$ of the participants suffered from urinary incontinence, only $42 \%$ felt the need to wear sanitary pads. Some participants felt too shy even to visit a doctor. Others had accepted their condition and no longer complained about it.

The study shows that women could benefit from more information about genital prolapse and the treatment options. Information leaflets would probably reassure women that they are not alone, that their situation is not normal and that something can be done about it. The information could possibly give them more confidence to discuss their condition with experts.

Nurses, doctors and other health care workers must be made aware of the uniqueness of each patient and that not everyone experiences symptoms in the same way.

All participants in this study expressed concerns about possible operations that could be performed to repair genital prolapse. Although not included in this article, their opinions and concerns regarding this matter must be addressed.

\section{Bibliography}

BABBIE, E 2004. The Practice of Social Research. $10^{\text {th }}$ Edition. Belmont: Thomson Wadsworth.

BASSETT, C 2004. Qualitative Research in Healht Care. Philadelphia: Wiley.

BARBER, MD; KUCHIBHATLA, MN; PIEPER, CF \& BUMP, RC 2001. Psychometric evaluation of 2 comprehensive condition-specific quality of life instruments for women with pelvic floor disorders. American Journal of Obstetrics and Gynecology. 185(b):1388-1395.

BONETTI, TR; ERPELDING, A \& PATHAK, LR 2004. Listening to "Felt Needs": Investigating Genital Prolapse in Western Nepal. Reproductive Health Matters. 12(23). 166-175.

BRINK, H 2006. Fundamentals of research methodology for Health Care professionals. Cape Town: Juta \& Co. 
BURNS, N \& GROVE, SK 2005. The practice of Nursing Research. Fourth Edition. Pennsylvania: W.B. Saunders Company.

CASH, TF \& PRUZINSKY, T 2002. Body Image- A handbook of Theory, Research and Clinical Practice. New York: The Guilfred press.

DE VOS, AS; STRYDOM, H; FOUCHé, SB \& DELPROT, CSL 2004. Research at Grass Roots. Second Edition. Pretoria: Van Schaik Publishers.

DONOHUE, M 2001. Pelvic Organ Prolapse May Not Correlate With Defect Location. Obstetric and Gynecology News. May 2001.

DOUGHTY, DB 2000. Urinary \& Fecal Incontinence Nursing Management, Second Edition. Missourie: Mosby, Inc.

DOYLE, JK 2001. Introduction to Interviewing Techniques. Handbook for IQP Advisors and Students. www.wpi.edu/Academics/Depts/IGSD/ IQPHbook/chl la.html .

DRIFE, J \& MAGOWAN, B 2004. Clinical Obstetrics and Gynaecology. London: Elsevier Limited.

DUGAN, E; ROBERTS, CP; COHEN, SJ; PRESSER, JS; DAVIS, CC; BLAND, DR \& ALBERTSON, E 2002. Why Older Community-Dwelling Adults Do Not Discuss Urinary Incontinence With Their Primary Care Physicians. The Journal of Age Related Disorders. 14(5):36.

ELLERKMAN, RM; CUNDIFF, GW; MELICK, CF; NIHIRA, MA; LEFFLER, $K$ \& BENT, AE 2001. Correlation of symptoms with location and severity of pelvic organ prolapse. American Journal of Obstetrics and Gynecology. 185:13221338.

HAMPEL, C; ARTIBANI, W; PONS, ME; HAAB, F; JACKSON, S; ROMERO, J; GAVART, $S \&$ PAPANICAOU, $S$ 2004. Understanding the Burden of Stress Urinary Incontinence in Europe: A Qualitative Review of the Literature. European Urology. 46:15-27.

KUMARI,S; WALIA, I \& SINGH,A2000. Self-Reported Uterine Prolapse in a Resettlement Colony of North India.
Journal of Midwifery \& Women's Health. 45(4):343-350.

MCCARTHY, A \& HUNTER, B 2003. Obstetrics and Gynaecology. London: Elsevier Limited.

MESCHIA, M; BUONAGUIDI, A; PIFAROTTI, P; SOMIGLIANA, E; SPENNACCHIO, M\&AMICARELLI, F 2002. Prevalence of Anal Incontinence in Women with Symptoms of Urinary Incontinence and Genital Prolapse. Obstetrics and Gynecology. 100:719-723.

MORRIS, CG \& MAIST, AA 2002. Psychology an Introduction. New Jersey: Prentice Hall.

NEWMAN,DK \& GIOVANNINI, D 2002. The Overactive Bladder: A Nursing Perspective. American Journal of Nursing. 102(6):36-45.

POLIT, DF \& BECK, CT 2004. Nursing Research Principles and Methods. $7^{\text {th }}$ Edition. Philadelphia: Lippincott Williams and Wilkens.

SCOTT, JR; DISAIA, PJ; HAMMOND, CB \& SPELLACY, WN 1999. Danforth's Obstetrics \& Gynecology. Philadelphia: Lippincott Williams and Wilkens.

SILVERMAN, D 2005. Doing Qualitative Research Second Edition. London: Sage Publications Ltd.

SPEZIALE \& CARPENTER 2003. Qualitative Research in Nursing. Third Edition. Philiadeiphia: Lippincot Williams \& Wilkins.

THAKAR, R \& STANTON, S 2002. Management of genital prolapse. British Medical Journal. 324:1258-1262. 